\title{
Os sistemas de bilhetagem eletrônica e suas múltiplas dimensões: um estudo sobre o SBE da região metropolitana do Recife
}

\section{RESUMO}

A implantação dos sistemas de bilhetagem eletrônica (SBEs) envolve uma série de escolhas além daquelas de ordem técnica. Para ampliar a compreensão desses sistemas, pesquisou-se o Vale Eletrônico Metropolitano (VEM), do SBE, da Região Metropolitana do Recife, com base na teoria da construção social da tecnologia e na teoria do discurso, que permitiram conhecer as dimensões sociais e políticas do referido Sistema. Isso sob a justificativa de que tal conhecimento poderá servir de base para a implementação de práticas mais adequadas à gestão desses sistemas. Para analisar a construção dos discursos pelos agentes relevantes do Sistema, utilizaram-se, como corpus, os sites dos SBEs, artigos de especialistas, notícias da imprensa escrita e entrevistas com agentes do sistema de bilhetagem. Após a análise das demandas, convergências, particularidades e antagonismos encontrados nos discursos sobre o SBE da RMR, concluiu-se que se trata de um sistema cuja articulação ocorre em torno de demandas relacionadas a funcionalidades operacionais - controle e fiscalização -, deixando de fora outras demandas, dentre as quais aquelas que poderiam atender mais diretamente às demandas por mobilidade dos usuários.

Palavras-chave: Sistema de Bilhetagem Eletrônica. Teoria do Discurso. Construção Social da Tecnologia.

Maria Irae Souza Corrêa mariairae@hotmail.com 


\section{INTRODUÇÃO}

Os sistemas de bilhetagem eletrônica (SBEs) têm sido considerados elementos propulsores do desenvolvimento dos sistemas inteligentes em transportes (ITS) na última década (ANTP, 2012). Destacam-se em importância pela capilaridade pela sua inserção nos ônibus, veículos responsáveis por aproximadamente $95 \%$ dos deslocamentos por transportes públicos, de acordo com levantamentos da Associação Nacional de Transportes Públicos (ANTP, 2007). Na última década, os SBEs tiveram vertiginosa expansão, como apontam os levantamentos realizados pela ANTP (NTU, 2010): enquanto em 2010 estavam presentes em cerca de 70\% das cidades com mais de cem mil habitantes, de acordo com pesquisa publicada pela associação, atualmente, conforme Martinelli e Aroucha (2012), os SBEs fazem parte de $77 \%$ dos municípios com mais de cinquenta mil habitantes.

De modo geral, as vantagens do uso da bilhetagem eletrônica têm sido relacionadas ao aumento da segurança nos veículos, por causa da menor quantidade de dinheiro em circulação; maior rapidez no embarque, já que o sistema dispensa o troco; redução do custo operacional; geração e controle das informações sobre os usuários, monitorando sua presença no sistema; facilidades para a flexibilização da tarifa única. Segundo Asquini e Fonseca (2005), com todas essas vantagens, os SBEs passaram a contribuir para a mobilidade urbana, fenômeno que emerge como uma das principais preocupações contemporâneas.

Um estudo exploratório realizado por Corrêa (2013) em cem sistemas de bilhetagem eletrônica mostrou que, de modo geral, os cartões de identificação definidos nesses sistemas são vinculados ao controle das isenções tarifárias legais. Todos os cem sistemas pesquisados possuíam um cartão para substituir o vale-transporte de papel. Oitenta e quatro por cento possuíam cartões destinados a estudantes, $75 \%$ destinam cartões a idosos e $72 \%$ aos portadores de necessidades especiais. Em menor proporção, acompanhantes de portadores de necessidades especiais, 20\%; professores, $15 \%$; crianças, $8 \%$. O cartão comum, destinado ao pagamento da passagem integral, o único não relacionado aos benefícios legais, esteve presente em $86 \%$ dos sistemas. Apenas em poucos casos, os SBEs emitiram cartões relacionados a contextos específicos das cidades nas quais foram implantados. Foram observados, então, cartões para localidades turísticas, tais como o cartão Passe Rápido Turista, em Florianópolis/SC e Foz do Iguaçu/PR. Em Natal/RN, foi criado um cartão para uma categoria de trabalhador, o NatalCard Profissionais Liberais. Outros, menos óbvios, como o bilhete único para obesos e gestantes, das cidades de São Paulo/SP e Carapicuíba/SP, respectivamente.

No referido estudo, identificam-se alguns sistemas de bilhetagem eletrônica nos quais os recursos tecnológicos foram direcionados para novas formas de utilização. Dentre elas, pode-se citar a possibilidade de inserir créditos comuns em cartões com benefícios tarifários, no caso de Blumenau/ SC. O uso da biometria para a identificação dos usuários dos cartões, que ocorre no Mais Aracaju Vale Estudantil, em Aracaju/SE, ou o cartão com novas políticas tarifárias, como o da Baixada Santista, no estado de São Paulo, no qual os usuários são tarifados de acordo com o trajeto percorrido; ou, ainda, cartões com integração temporal de tarifas, como em Porto Alegre/RS, por exemplo. Alguns cartões de bilhetagem eletrônica tiveram ampliadas as suas funções, sendo utilizados como cartão de crédito, conforme ocorre em Santa Luzia/MG.

Diante de tantas variações possíveis, surgiram alguns questionamentos acerca dos processos de definição das configurações dos sistemas de bilhetagem eletrônica. Como é possível que um sistema de bilhetagem voltado para a eficiência do sistema de transporte apresente tantas variações? Como ocorrem os processos de definição relacionados às configurações dos cartões? Por que apenas em algumas poucas cidades a implantação do SBE resultou na produção de informações que possibilitam a flexibilização das políticas tarifárias? Por que a alguns grupos da população são destinados cartões específicos e a outros não?

As pesquisas sobre sistemas de bilhetagem eletrônica têm sido relacionadas ao campo de estudos dos sistemas de informação (ANTP, 2012; LUBECK; LADEIRA; COSTA, 2008). Entretanto, como se pôde observar no estudo exploratório, a implantação dos SBEs envolve uma série de escolhas, além daquelas de ordem técnica, tornando evidente que a compreensão do modo como se dá a configuração dos SBEs ultrapassa o corpo de conhecimento daquele campo. Outras dimensões sociais e políticas fazem-se presentes na configuração desses sistemas; assim, propõe-se que tais sistemas, para serem mais bem compreendidos, devem ser investigados em suas múltiplas dimensões, a partir das articulações necessárias para acomodar os diferentes interesses dos agentes envolvidos.

Considera-se que a teoria da construção social da tecnologia (BIJKER; HUGHES; PINCH, 1987), com seus conceitos de agentes relevantes, quadro tecnológico, flexibilidade interpretativa e fechamento, em diálogo com a teoria do discurso (LACLAU; MOUFFE, 2001) com seus conceitos de hegemonia, articulação, cadeia de equivalência, contribuem para o entendimento dos sistemas de bilhetagem em suas múltiplas dimensões. Dentro dessa perspectiva, de modo a compreender as 
articulações que tornam possível as configurações dos SBEs, tomou-se como objeto de investigação o SBE da Região Metropolitana de Recife (RMR). A Região tem sido considerada uma das pioneiras no que se refere à bilhetagem eletrônica e à gestão dos transportes públicos (GAMA; RECENA; ELOY, 2005). Seu sistema de bilhetagem é um dos mais antigos do Brasil, foi implantado em março de 1999, ainda sob a gestão da Empresa Municipal de Transportes Urbanos (EMTU). Conhecido como Sistema Automático de Bilhetagem Eletrônica (SABE), esteve voltado inicialmente para motoristas, cobradores e fiscais e, num segundo momento, em maio de 2000, os estudantes foram incorporados ao sistema, com um cartão eletrônico de identificação que substituiu o passe estudantil.

Assim, o objetivo desta pesquisa é compreender as articulações que tornaram possível a configuração do SBE da Região Metropolitana do Recife. Para isso, serão identificados os agentes relevantes do sistema de bilhetagem eletrônica, as demandas convergentes, particulares e antagônicas desses agentes em relação ao sistema de bilhetagem e o modo como essas demandas foram articuladas no referido sistema.

\section{DOS SISTEMAS TECNOLÓGICOS AOS SISTEMAS DISCURSIVOS}

Nos anos 1980, novas perspectivas foram somadas ao debate acerca das relações entre tecnologia e sociedade, sobrepondo-se e, em certo sentido, modificando os caminhos do debate existente. Como assinala Benakouche (1999), o foco passou a ser a análise do processo de produção e difusão dos objetos técnicos. Dentro dessa orientação, tem-se a conhecida metáfora latouriana de "abrir a caixa preta", para se referir ao processo pelo qual se busca compreender como, em meio às interações sociais que ocorrem no contexto da produção da ciência, as verdades técnicas e científicas são estabelecidas. Nessa mesma direção, os autores da construção social da tecnologia (BIJKER; HUGHES; PINCH; 1987) defendem que artefatos tecnológicos são construídos, acima de tudo, por processos sociais e que, por isso, não é possível separar completamente os elementos sociais dos elementos tecnológicos. Fundamentos da teoria dos sistemas contribuíram para o desenvolvimento de novas perspectivas em relação ao modo como a tecnologia opera, a partir da ideia de que, para serem produzidos e para funcionar, os objetos dependem de um conjunto de relações sociais, às quais se encontram enraizados.

Em um estudo pioneiro sobre a tecnologia como sistema, com base na análise da expansão das redes de eletricidade nos Estados Unidos e em países europeus, Hughes (1987) desenvolveu o conceito de sistemas tecnológicos utilizado na teoria da construção social da tecnologia. Tais sistemas incluem desde recursos naturais, como minas de carvão, por exemplo, passando pelos artefatos fabricados, tais como geradores, linhas de transmissão de luz elétrica, e também organizações fabricantes, distribuidoras ou financiadoras dos produtos. Além disso, os sistemas incorporam a produção científica de livros, artigos e programas acadêmicos de ensino e pesquisa, e também leis, normas, resoluções que regulam o setor. A ideia da tecnologia como sistema mostra que adotar uma solução tecnológica, como aponta Winner (1985), envolve também escolhas econômicas, políticas, culturais ao lado daquelas que são consideradas técnicas. Tais considerações podem ser aplicadas aos sistemas de transportes, uma vez que estes abrangem não apenas a opção por tipos de veículo, mas dizem respeito a diversas cadeias produtivas, incluindo desde matrizes energéticas até modelos de traçado urbano.

A abordagem dos sistemas tecnológicos fundamenta-se na ideia de que ao mesmo tempo em que são influenciados pelos processos sociais, eles mudam a configuração da sociedade em que são produzidos, construindo socialmente o contexto. Os autores da construção social da tecnologia têm sido criticados porque, apesar de se oporem a visões deterministas das relações entre tecnologia e sociedade, não conseguiram escapar totalmente delas (BENAKOUCHE, 1999), em especial quando consideram os sistemas tecnológicos como motor da mudança social, como parece ser o caso do trabalho de Hughes (1987). Ainda de acordo com a autora, a ideia de determinismo advém do conceito de sistema e de sua noção de autorregulação, que pode aproximá-lo de um processo autônomo em relação ao social. $\mathrm{E}$, de fato, vários autores sustentam que, a partir de um determinado estágio, os sistemas técnicos adquirem uma dinâmica própria, tornando difícil, e muitas vezes impossível, manter um controle sobre eles.

Latour (1987) e outros autores da teoria ator-rede (TAR) trabalham com o conceito de rede, considerado mais flexível no que concerne à alusão determinista da perspectiva sistêmica. Por outro lado, Benakouche (1999) considera que o conceito de sistema favorece o foco nas relações de interdependência envolvidas na produção e funcionamento de artefatos técnicos, evitando-se o reducionismo da ênfase no objeto. Nesse sentido, tal conceito é indispensável para a compreensão de objetos como, por exemplo, o automóvel, pois aponta para um conjunto gigantesco envolvendo 
a produção, a manutenção e a comercialização dos veículos, e os empregos correspondentes, a construção, a manutenção e a fiscalização das estradas, a produção e a distribuição dos combustíveis, a formação dos condutores, as leis de trânsito e as disputas jurídicas que as envolvem, a regulação do trânsito urbano e a sinalização correspondente, os problemas urbanísticos do trânsito e do estacionamento, a poluição do ar e as doenças decorrentes, etc. Assim, o conceito de sistema favorece a compreensão dos mecanismos próprios aos conjuntos organizados, atenta para fatores que orientam o desenvolvimento de novas estruturas em razão de necessidades internas das estruturas existentes.

Desse modo, as relações entre tecnologia e sociedade, com base na teoria da construção social da tecnologia, são pensadas fora do instrumentalismo ou do determinismo, reconhecendo a agência humana, ainda que esta se encontre moldada pela força estruturante dos sistemas. Para compreender o desenvolvimento de artefatos tecnológicos, Bijker, Hughes e Pinch (1987) criaram os conceitos de grupos sociais relevantes, que são os grupos que interagem diretamente com os artefatos e lhes atribuem significados; flexibilidade interpretativa, que se refere às diferentes significações possíveis atribuídas pelos grupos relevantes aos artefatos, e estabilização e fechamento, conceitos que nomeiam o momento da definição final dos artefatos. Esse processo ocorre dentro de um contexto chamado pelos autores de estrutura tecnológica.

Por outro lado, consideramos que a teoria do discurso, desenvolvida por Ernesto Laclau e Mouffe (2001), pode trazer importantes contribuições para a discussão, uma vez que os autores desenvolveram uma série de conceitos que ajudam a pensar o processo que envolve a configuração dos sistemas de bilhetagem eletrônica.

A teoria do discurso foi desenvolvida na década de 80, no contexto dos esforços para compreender a emergência de uma nova lógica do social com base nas transformações estruturais na sociedade contemporânea. Alinhados ao pós-marxismo, os autores questionam as ideias marxistas clássicas relacionadas a um devir histórico e defendem que agentes e sistemas são construções sociais que passam por constantes mudanças como resultado de práticas políticas, sendo impossível atribuirIhes uma agência necessária diante do contexto singular de tais práticas. Para a compreensão desses processos contingentes, os teóricos do discurso desenvolveram conceitos-chave, que foram tomados como base no presente estudo, são eles: discurso, cadeia de equivalência, hegemonia, práticas articulatórias e antagonismo.

O conceito de discurso parte da ideia de que as pessoas são introduzidas em um mundo de objetos e práticas com significados socialmente atribuídos e não podem pensar sobre eles fora desse contexto de significados (HOWARTH; STAVRAKAKIS, 2000). Estes são dados por um sistema de relações, histórico e contingente, do qual participam palavras e práticas que, por sua vez, integram uma configuração mais ampla que lhes confere sentido e estabelece quais serão as relações entre elas. O processo de significação, contudo, não pode ser completamente esgotado, a linguagem como um sistema simbólico não permite esse fechamento, uma vez que a representação do real ocorre por meio de uma lógica que deixa de fora aquilo que a excede, como aborda a teoria lacaniana (GLYNOS, 2001). Essa abertura torna possível que objetos e práticas sejam ressignificados e, nesse processo, ocorram disputas pela imposição de significados.

Três elementos centrais compõem o processo de significação e a formação do discurso: o significante flutuante, ou o distanciamento do significante hegemônico de um significado preciso para que, nessa condição, possa representar os outros significantes, no caso, as outras demandas que constituem a cadeia de equivalência; a construção dessa cadeia estabelecida com base na convergência de demandas comuns; e a hegemonia, que é o processo pelo qual uma demanda passa a representar todas as outras.

Laclau (2006) explica que o caminho para o entendimento da formação da cadeia de equivalência é considerar que, em uma situação inicial, diferentes grupos possuem suas demandas específicas em relação a um exterior constitutivo, demandas que podem não estar sendo atendidas naquele contexto. Nessas condições, os grupos com suas demandas específicas, tomados separadamente, são chamados de 'elementos'.

Laclau e Mouffe (2001) consideram que, das práticas que articulam os significados, emergem as identidades; na verdade, trata-se de uma rearticulação porque os significados sempre estiveram articulados de algum modo. Desse modo, um discurso pode ser entendido como uma totalidade estruturada, resultado de práticas articulatórias, no interior dos quais as identidades são construídas. Para entender como um dos elementos da cadeia assume a função da totalidade das demandas que participam da equivalência, a hegemonia é um conceito central. Em sua formulação, originária da tradição do pensamento marxista russo, a hegemonia foi um conceito utilizado no sentido tático, para agregar diversas forças em torno da classe operária, em uma situação que não se desenvolveu conforme as leis necessárias do materialismo histórico, mas de contingências e indeterminações do contexto russo. 
Em uma perspectiva histórica do conceito, Burity (1997, p. 11) lembra que, tempos depois, Gramsci integra a ele a ideia de liderança intelectual e moral, "na medida em que [hegemonia] exige certo 'consenso' em torno de 'ideias' e 'valores' que atravessem posições de classe". No pensamento pósmarxista, o conceito de hegemonia passa a ter o caráter de lógica do social, um processo constituinte contingente com base nas práticas articulatórias. A demanda hegemônica assume o papel de representar a cadeia de equivalência e, quanto mais estendida for essa cadeia, menos a demanda hegemônica manterá vínculos com sua particularidade original, uma vez que precisa desvincularse de significados específicos para representar a totalidade. Sem aquelas referências originais, o significante que representa a demanda hegemônica torna-se vago e impreciso, transforma-se em um significante flutuante.

Outra consideração importante a respeito do modelo de análise da teoria do discurso é que uma das simplificações que o torna possível é a suposta estabilidade das fronteiras. Contudo, em se tratando de um campo de disputas, é necessário ter em mente que aqueles que estão no outro lado da fronteira vão tentar desestabilizá-la, criando outra fronteira. Essa demanda pela qual competem as cadeias de equivalência está submetida então à pressão estrutural das duas e passa a ter uma significação indefinida no sistema político.

A incorporação de demandas não pode ser automática em virtude de essas possuírem uma dimensão particular, que integra de modo latente a cadeia de equivalência, e que pode impedir a incorporação de outras demandas que com elas entrem em choque. Desse modo, a cadeia de equivalência torna-se limitada por causa de conflitos entre uma e outra demanda que, ao final, prevalecem sobre as tendências à unidade. $E$, assim, tem-se a situação em que certas demandas não podem incorporar-se à cadeia de equivalência porque suas particularidades são exteriores ao processo de representação.

De modo a argumentar acerca de um diálogo possível entre as teorias do discurso e a da construção social da tecnologia, para que aquela supra as lacunas desta, fornecendo os conceitos para se compreender a natureza política dos sistemas tecnológicos, Marçal (2014) propõe alguns pontos de aproximação, com base nos quais se pode pensar a articulação teórica entre as duas perspectivas. Começando pelos condicionantes estruturais, enquanto os construtivistas reconhecem um quadro tecnológico, ou uma estrutura de significação, no interior da qual são concebidas as tecnologias, Laclau e Mouffe (2001) definem as estruturas como campo discursivo, o espaço constitutivo das práticas articulatórias, que configuram o horizonte do qual os eventos são significados.

Tais estruturas constituem e são constituídas por agentes que, na medida em que ocupam distintas posições, possuem diferentes perspectivas, interesses e demandas, estabelecendo relações de disputa em torno de definições relacionadas à construção de sistemas tecnológicos. Nesse sentido, podem-se aproximar as categorias de agentes relevantes, dos construtivistas, com a de sujeito, dos teóricos do discurso, relacionando-as à agência das pessoas sobre as estruturas discursivo-tecnológicas, o que ocorre por meio das disputas em torno dos significados atribuídos aos objetos técnicos que compõem tais sistemas.

Para entender os processos subjacentes a essas disputas, utilizou-se outra aproximação conceitual possível: entre as categorias de flexibilidade interpretativa e significante flutuante. A primeira, como apresentado anteriormente, refere-se ao fato de que, no processo de desenvolvimento do artefato, os agentes produzem diferentes interpretações sobre ele, de seus diferentes pontos de vista. Esse conceito aproxima-se do conceito de significante flutuante na medida em que em ambos estão relacionados a diversas possibilidades que disputam a significação de um evento/artefato. Com isso, ambas as teorias reconhecem a importância do processo interpretativo nas definições dos eventos sociais, o que inclui o desenvolvimento dos sistemas tecnológicos.

E, por fim, ainda de acordo com Marçal (2014), outra possibilidade de aproximação ocorre entre os conceitos de fechamento, na construção social da tecnologia, e hegemonia, na teoria do discurso. O fechamento é aquele ponto não reversível do processo discordante sobre a configuração dos artefatos, que representa o estabelecimento de um arranjo possível, com base em negociações entre os agentes relevantes. O conceito de hegemonia, como observado, nomeia a supremacia de um grupo, conquistada com base em um acordo possível, resultado de uma articulação entre diferenças. Nesse momento, pode-se situar a contribuição da TD com seus conceitos que ajudam a pensar como é possível esse fechamento ou a construção da hegemonia, já que se trata de uma teoria para pensar o político. O conceito de cadeia de equivalência cumpre esse papel, sem um correspondente na construção social da tecnologia. Isso porque nomeia a lógica com base na qual é possível haver uma articulação, tendo em vista elementos convergentes, particulares e antagônicos, de demandas em disputa.

A teoria da construção social da tecnologia ajuda-nos a compreender os sistemas tecnológicos no contexto de práticas sociais; enquanto a teoria do discurso enfatiza sua lógica política. Além 
disso, a teoria do discurso, com suas raízes pós-estruturalistas, colabora para a compreensão das relações entre os sistemas tecnológicos e as subjetividades contemporâneas, tema que a construção social da tecnologia não aborda. Assim, essas duas teorias foram aproximadas de modo a construir um referencial teórico que amplie a compreensão acerca dos Sistemas de Bilhetagem Eletrônica. A natureza do objeto, um sistema tecnológico, leva, por um lado, a lançar mão de autores que teorizaram a propósito da construção social da tecnologia, que contribuíram com seus estudos no campo temático da produção da tecnologia, dentro de uma perspectiva crítica. Por outro lado, a teoria do discurso fornece a base onto-epistemológica e os conceitos para pensar a natureza política dos sistemas de bilhetagem eletrônica.

Tal referencial teórico ajuda a problematizar as ideias instrumentalistas e deterministas acerca de eficiência e de solução técnica, como único ponto de chegada ao desenvolvimento tecnológico, apontando caminhos com base nos quais diferentes soluções podem ser pensadas, mas sempre em um solo espaço-temporal socialmente construído e permeado de interesses. Trata-se de um ponto importante para a argumentação que aqui foi desenvolvida, defendendo os SBEs como sistemas discursivos, pela indeterminação e instabilidade de seu processo de significação, o que pôde ser feito com auxílio do aparato conceitual da teoria do discurso.

\section{O SISTEMA DE BILHETAGEM ELETRÔNICA DA RMR}

Na última década, a gestão dos transportes públicos na Região Metropolitana do Recife passou por diversas mudanças, com a criação do Consórcio Grande Recife, formado pela EMTU, Empresa Municipal de Transporte do Recife e por prefeituras da Região Metropolitana. O Consórcio tornou-se responsável pelo planejamento, gestão e implementação da política de transporte público coletivo na RMR. Como analisa Best (2011), trata-se de um processo potencialmente inovador no que se refere à gestão pública, levando-se em conta a dificuldade de articulação entre os municípios da maior parte dos centros urbanos do país.

No contexto dessas mudanças, ocorreu a implantação de um novo sistema de bilhetagem eletrônica, conhecido como SBE e a criação de um novo cartão, o Vale Eletrônico Metropolitano (VEM), no fim de 2008. Com o novo sistema, as empresas de ônibus que atuam em Recife e Região Metropolitana passaram a integrar um mesmo sistema para cadastramento do usuário e a emissão dos cartões de acesso, o monitoramento das garagens, geração de relatórios e comunicação com os sistemas das empresas, entre outras funções. Para o VEM, foram planejadas seis categorias de identificação descritas no site do cartão pelas características apresentadas no Quadro 1.

Quadro 1 - Tipos de Vale Eletrônico Metropolitano

\begin{tabular}{|l|l|}
\hline \multicolumn{1}{|c|}{ Tipos } & \multicolumn{1}{c|}{ Características } \\
\hline $\begin{array}{l}\text { VEM } \\
\text { Trabalhador }\end{array}$ & $\begin{array}{l}\text { Substitui o vale-transporte, fornecido pelo empregador, mas em caso de } \\
\text { desligamento, permanece com o trabalhador, que poderá utilizá-lo em outro } \\
\text { emprego, sendo, portanto, um documento pessoal. }\end{array}$ \\
\hline $\begin{array}{l}\text { VEM } \\
\text { Estudante }\end{array}$ & $\begin{array}{l}\text { Substitui o passe estudantil, voltado aos alunos matriculados em instituições } \\
\text { de ensino que estejam cadastradas no sistema do Consórcio de Transportes. }\end{array}$ \\
\hline $\begin{array}{l}\text { VEM } \\
\text { Idoso }\end{array}$ & $\begin{array}{l}\text { Destinado aos passageiros que tenham } 65 \text { anos ou mais, cujo acesso gratuito } \\
\text { deixa de estar restrito aos bancos dianteiros do ônibus. }\end{array}$ \\
\hline $\begin{array}{l}\text { VEM } \\
\text { Infantil }\end{array}$ & $\begin{array}{l}\text { Para menores de seis anos, que não precisarão mais passar por baixo da catraca } \\
\text { para ter direito ao transporte gratuito. }\end{array}$ \\
\hline $\begin{array}{l}\text { VEM } \\
\text { Especial }\end{array}$ & $\begin{array}{l}\text { Substitui a carteira de livre acesso. Permite que pessoas com deficiência física, } \\
\text { mental ou sensorial utilizem o sistema gratuitamente, com o acesso não } \\
\text { apenas aos bancos da frente do ônibus. }\end{array}$ \\
\hline $\begin{array}{l}\text { VEM } \\
\text { Comum }\end{array}$ & $\begin{array}{l}\text { Destinado ao passageiro que não se enquadra nas categorias anteriores, e } \\
\text { que paga o valor integral pela tarifa. Este modelo pode ser utilizado por outra } \\
\text { pessoa que não o titular, portanto não é um documento pessoal. }\end{array}$ \\
\hline
\end{tabular}

Fonte: VALE ELETRÔNICO METROPOLITANO (2014)

Dos seis cartões já planejados desde a implantação do atual SBE, até o momento, quatro estão em operação: o VEM Comum, o VEM Trabalhador, o VEM Estudante e o VEM Infantil. Os cartões destinados aos idosos e aos portadores de necessidades especiais, usuários com isenções previstas 
em lei, ainda não estão disponíveis para os usuários do sistema, apesar da reconhecida importância do controle das gratuidades para o equilíbrio das operações do sistema de transporte.

Como observado, a expansão dos sistemas de bilhetagem eletrônica tem sido associada à eficiência, voltada para a solução de problemas de mobilidade urbana. Contudo, as configurações atualmente observadas nos SBEs estão voltadas para o controle da utilização dos benefícios tarifários. Sinal disso é o princípio utilizado para a definição dos cartões de identificação, de natureza ocupacional e demográfica, que não guarda relações com padrões de deslocamento ou nenhum outro critério relacionado às mobilidades pessoais. Por outro lado, os cartões estabelecem categorizações sociais e as regras de uso que poderão interferir nas mobilidades pessoais dos usuários.

\section{PROCEDIMENTOS METODOLÓGICOS}

A pesquisa qualitativa e sua abertura para a compreensão dos fenômenos sociais corresponde à abordagem coerente com a fundamentação teórica deste trabalho, baseada em teorias interpretativistas. Os procedimentos metodológicos e analíticos foram inspirados nas teorias mencionadas, pois ambas além de teorias são consideradas métodos de análise. A teoria da construção social da tecnologia, de Bijker, Hughes e Pinch (1987), e a teoria do discurso, de Laclau e Mouffe (2001), auxiliaram-nos na identificação dos agentes relevantes do SBE da Região Metropolitana do Recife, bem como na análise de como suas demandas encontram-se articuladas.

Para a construção do corpus analítico, foi realizada uma pesquisa documental em diversas fontes relacionadas ao tema. Iniciou-se com uma pesquisa nos sites dos Sistemas de Bilhetagem Eletrônica das cidades brasileiras; em seguida, partiu-se para a análise de artigos de técnicos/especialistas publicados pela ANTP/NTU sobre bilhetagem eletrônica. Foi realizado também um levantamento em publicações dos jornais diários da imprensa pernambucana e, por último, leitura das atas do CSTM, o Conselho Superior dos Transportes Metropolitanos, órgão deliberativo do Consórcio Grande Recife, especificamente de atas de reuniões que tratavam sobre bilhetagem eletrônica. Após esse levantamento de documentos, em um segundo momento, realizaram-se entrevistas em profundidade com os agentes relevantes do SBE, definidos de acordo com a teoria e identificados na primeira etapa. Nessa fase, os entrevistados foram os gestores das seguintes entidades: Consórcio Grande Recife, do Sindicato das Empresas de Ônibus (URBANA), empresas de transporte, empresas que utilizam o SBE para seus funcionários, empresas de TI e usuários do sistema de bilhetagem. Para a identificação desses agentes, utilizou-se o procedimento conhecido como bola de neve, segundo o qual se obtém gradativamente o nome de novos entrevistados pela indicação de entrevistados anteriores, até que, em um dado momento, novos nomes deixarão de aparecer e teremos um conjunto representativo de agentes envolvidos.

Os procedimentos para a análise dos documentos seguiram os princípios da análise de discurso de matriz francesa (AD), em virtude das intersecções importantes entre esse campo de conhecimento e a teoria do discurso, referencial deste trabalho. A teoria do discurso aproxima-se de objetos textuais, tais como relatórios, entrevistas, documentos públicos, comunicações oficiais, entre outros, de modo que esses evidenciam processos de delimitação de fronteiras, o estabelecimento de cadeias de equivalência, a construção de identidades, expressões de antagonismo, contingências, deslocamentos, que são as categorias com base nas quais se evidencia a lógica política do social.

A análise do discurso orientou o modo como foram estabelecidas relações entre a discursividade e a textualidade presentes no campo em estudo. Os procedimentos estão centrados nas ideias de Orlandi (2002), sobre o funcionamento da linguagem e seus mecanismos de constituição de sentidos e de sujeitos. Nesses procedimentos, em uma primeira etapa, o pesquisador empreende o processo de desuperficialização do texto, no qual irá analisar quem diz, o que diz, como diz, para quem diz e em que circunstâncias diz. Nesse momento, o analista busca desnaturalizar as relações entre as palavras e coisas estabelecidas pelo texto, mostrando que aquilo que está sendo dito de determinada forma, poderia ser dito de outras maneiras, identificando interesses e demandas, e relacionando-as às posições ocupadas pelo sujeito.

Em uma etapa posterior, destacam-se os discursos que entrecruzam o campo em disputa e suas condições de produção, relacionando o que foi dito, o não dito e o silenciado, apontando convergências e antagonismos. Desse modo, o texto passa a ser relacionado a um campo discursivo mais amplo, no qual estão presentes diferentes discursos, com seus enunciados, que disputam a significação dos eventos. A partir desse ponto, a análise caminha para a terceira etapa, na qual são apresentados os mecanismos por meio dos quais os discursos encobrem sua incompletude e contingência, e como produzem o esquecimento das operações de articulação e deslocamento que condicionam sua própria formação, tornando-se dominante, a partir da relação de hegemonia que 
estabelece com outros discursos.

Neste trabalho, buscaram-se diferentes gêneros discursivos como forma de ampliar nossa capacidade de identificar os diversos discursos que constituem o Sistema de Bilhetagem Eletrônica. Supõe-se que, na complementaridade entre os gêneros, é possível que lacunas sejam preenchidas, ampliando os recursos de análise. No Quadro 2, sintetizamos os procedimentos de análise utilizados neste texto.

Quadro 2 - Procedimentos para análise de dados

\begin{tabular}{|c|c|c|}
\hline \multirow{2}{*}{ Corpus/fontes } & \multicolumn{2}{|c|}{ Processo analítico } \\
\hline & Conceitos-chave & Técnicas \\
\hline $\begin{array}{l}\text { 1. Sites dos Sistemas de Bilhetagem } \\
\text { Eletrônica das cidades brasileiras. } \\
\text { 2. Artigos de técnicos/especialistas } \\
\text { publicados na ANTP/NTU. } \\
\text { 3. Publicações nos jornais diários da } \\
\text { imprensa local. } \\
\text { 4. Atas do CSTM do GRCT. } \\
\text { 5.Entrevistas pessoais com os agentes } \\
\text { do SBE. }\end{array}$ & $\begin{array}{l}\text { Discurso } \\
\text { Prática Articulatória } \\
\text { Cadeia de Equivalência } \\
\text { Hegemonia } \\
\text { Antagonismo }\end{array}$ & $\begin{array}{l}\text { Análise de Discurso } \\
\text { 1. De-superficialização } \\
\text { 2. Identificação de diferentes } \\
\text { discursos e o modo como se } \\
\text { relacionam. } \\
\text { 3. "Hegemonização". } \\
\text { Processos que encobrem a } \\
\text { incompletude e contingência } \\
\text { e naturalizam os discursos. }\end{array}$ \\
\hline
\end{tabular}

Fonte: Corrêa $(2013$, p. 69)

\section{ANÁLISE DOS RESULTADOS}

A seguir apresentamos a análise dos resultados. Na primeira seção, identificamos os agentes relevantes do sistema de bilhetagem eletrônica. Em seguida, relacionamos as demandas convergentes, particulares e antagônicas desses agentes e discutimos o modo como essas demandas foram articuladas no referido sistema.

\subsection{Agentes relevantes do SBE da Região Metropolitana do Recife}

Partiu-se da análise dos documentos do corpus de pesquisa, buscando, em primeiro lugar, identificar quais os agentes que estavam presentes nos sites dos SBEs implantados no Brasil. Um primeiro aspecto verificado nesse levantamento, realizado em julho de 2012, foi a multiplicidade de formas de gestão dos SBEs, distribuída entre sindicatos de empresas de transporte, consórcios, empresas públicas, empresas de transporte e empresas de tecnologia. Observou-se que $46 \%$ dos sistemas de bilhetagem eram geridos por associações privadas de empresas de transporte (sindicatos, cooperativas ou federações), $23 \%$ por consórcios entre órgãos públicos e privados, $14 \%$ por empresas públicas, no caso, empresas de trânsito e engenharia ou empresas de desenvolvimento urbano, e $14 \%$ eram geridos por empresas privadas de transporte. As empresas de tecnologia representavam apenas 3\% dos gestores dos SBEs no país.

Identificaram-se, nessas cinco categorias de gestores, potenciais agentes relevantes dos Sistemas de Bilhetagem, pois são eles que produzem, financiam ou administram os sistemas tecnológicos. Isso Ihes confere posição de destaque nas notícias sobre os SBEs veiculadas na imprensa. No Quadro 3, são apresentados os agentes sociais e a frequência com que foram encontrados em notícias sobre os SBEs em geral e sobre o VEM, sistema local. Nesse levantamento, buscou-se conhecer a participação de agentes já identificados e investigar novos possíveis agentes relevantes por meio de pesquisa em noticiário.

Quadro 3 - Síntese das notícias sobre os SBEs/VEM

\begin{tabular}{|l|c|c|}
\hline \multicolumn{1}{|c|}{ Agentes } & Geral (\%) & VEM (\%) \\
\hline Empresa de Transporte & 20 & 7 \\
\hline Prefeituras & 20 & 4 \\
\hline Movimentos Estudantis & 13 & 1 \\
\hline Movimentos Sociais & - & 2 \\
\hline Federação dos Aposentados & 13 & - \\
\hline
\end{tabular}




\begin{tabular}{|l|c|c|}
\hline Usuários de Transporte & 11 & 11 \\
\hline Consórcio & 7 & 25 \\
\hline Sindicatos & 4 & 4 \\
\hline Empresas Públicas & 4 & 5 \\
\hline Ministério Público & 2 & 5 \\
\hline Governo Federal e Estadual & 2 & 12 \\
\hline Bancos & - & 3 \\
\hline Empresa de Tecnologia & - & 7 \\
\hline $\begin{array}{l}\text { Cooperativa de transporte complementar/ } \\
\text { Permissionário }\end{array}$ & - & 8 \\
\hline Outros & 4 & 6 \\
\hline Total & 100 & 100 \\
\hline
\end{tabular}

Fonte: Corrêa (2013, p. 76)

Por meio do levantamento nas notícias da imprensa, foi confirmada a relevância dos agentes já identificados nos sites; ao mesmo tempo, surgiram outros agentes potencialmente relevantes, com destaque para os usuários e suas entidades coletivas, tais como movimentos estudantis, federação de aposentados, de deficientes, todos buscando influenciar nas decisões relacionadas às configurações dos SBEs. Além disso, sinalizando a importância das disputas que ocorrem entre os agentes no SBE da RMR, observou-se a presença do Ministério Público e de tribunais do Judiciário no noticiário.

Analisando especificamente o SBE da RMR, foram examinadas as atas do CSTM para verificar, dentro do Conselho, quais seriam os agentes que expressam interesses relacionados ao SBE nas reuniões deliberativas. Foi observado que, na maioria dessas atas, quem se pronuncia a propósito do sistema de bilhetagem é o próprio Consórcio, nas palavras de seu presidente ou de algum de seus diretores, embora se tenha observado também alguns poucos registros de falas dos usuários. Por fim, buscando agentes relevantes do SBE da RMR, identificaram-se outros grupos sociais durante a fase de entrevistas, seguindo o método bola de neve.

Assim, respondendo à questão relacionada a quem são os agentes relevantes do Sistema de Bilhetagem Eletrônica da RMR, com base no percurso investigativo dessa pesquisa identificaramse os seguintes agentes relevantes: Consórcio Grande Recife, Urbana, Empresas Operadoras, Empregadores, Empresas de Tecnologia e Usuários. Em virtude de suas posições econômica, técnica e política, são estes os grupos - produtores e usuários - responsáveis pelas decisões relacionadas à configuração do Sistema, aqueles em condições de imprimir significados ao artefato tecnológico (BIJKER; BAL; HENDRIKS, 2009), em que pese suas diferentes posições e simetrias.

Entres os agentes relevantes citados, podem-se considerar como agentes hegemônicos do SBE da RMR a Urbana e o Consórcio Grande Recife, tendo em vista suas condições legais e políticas para impor seus interesses na configuração do sistema.

\subsection{A articulação das demandas dos agentes do SBE da Região Metropolitana do Recife}

Com base na análise do corpus, foram identificadas as demandas convergentes, particulares e antagônicas dos agentes pesquisados relativamente às características do SBE da RMR. A seguir, é apresentado o modo como tais demandas foram articuladas para formar a cadeia de equivalência que tornou possível a constituição do SBE da RMR. A Figura 1 apresenta os agentes e seus interesses expressos em demandas, indicando que muitas delas são defendidas por mais de um grupo.

Os autores da teoria da construção social da tecnologia (BIJKER; HUGHES; PINCH, 1987) defendem que muitas configurações podem fornecer um artefato capaz de executar de modo eficiente certas funcionalidades. As definições em relação ao artefato relacionam-se aos interesses dos grupos relevantes, aqueles diretamente envolvidos na produção e no uso do artefato em questão. Então, como compreender o processo de fechamento em torno de uma configuração específica, tendo em vista a multiplicidade de demandas dos agentes relevantes?

De início, pode-se considerar que as demandas dos agentes no que concerne ao SBE possuem convergências, o que permite que, das práticas dos agentes envolvidos, se estabeleça uma cadeia de equivalências. Para isso, as particularidades devem ficar suspensas, de modo a possibilitar a articulação em torno de alguns pontos (LACLAU; MOUFFE, 2001), que, no caso em estudo, foram 
controle dos benefícios, facilidade na distribuição, produção de informações e segurança.

Figura 1 - Agentes relevantes e suas demandas

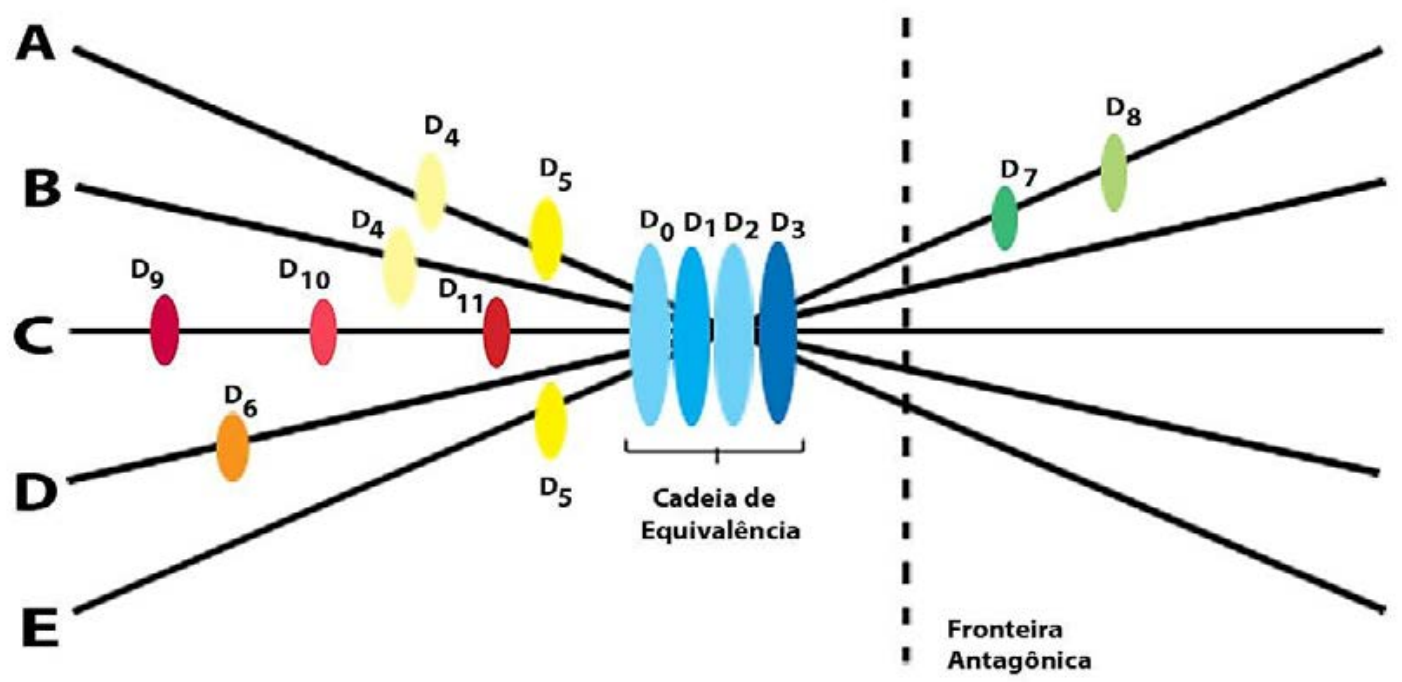

LEGENDA:

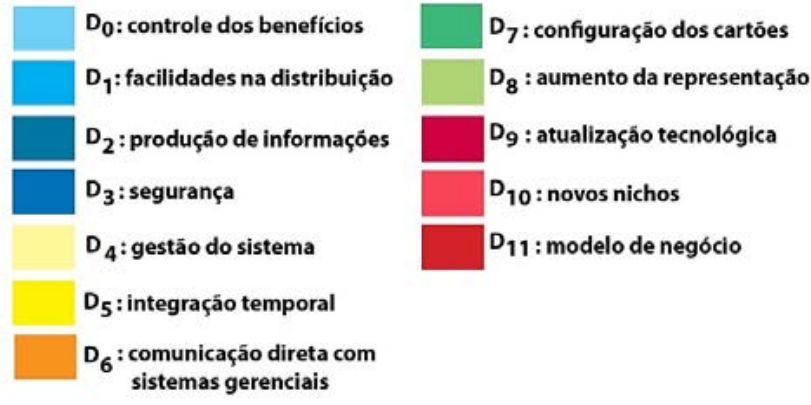

$A=$ Consórcio

$\mathrm{B}=$ Operadoras/Urbana

$C=$ Empresas de Tecnologia

$\mathrm{D}=$ Empregadores

$\mathrm{E}=$ Usuários

Fonte: Corrêa (2013, p. 125)

A demanda central diz respeito ao controle da utilização dos benefícios pelos usuários, pois em volta dela convergem interesses de todos os agentes relevantes do SBE. Em um primeiro plano, emergem os interesses do Consórcio e da Urbana que se articulam em torno da possibilidade de controlar o uso indevido das gratuidades e do vale transporte, contendo a evasão de recursos e moralizando o sistema. A coibição do uso indevido também atende aos interesses dos empregadores, uma vez que, como foi observado, o uso regular do vale transporte reduzirá as despesas com sua aquisição.

Mesmo entre os usuários, encontra-se a defesa da repressão dos abusos envolvendo as gratuidades, notadamente a falsificação das carteiras de Livre Acesso, pelo entendimento de que tais condutas trazem prejuízos financeiros aos próprios usuários, porque levam ao encarecimento do preço das passagens. Por sua vez, as empresas de tecnologia compartilham da demanda por controle da utilização dos benefícios pelos usuários do Sistema, na medida em que esse controle requer a atualização das tecnologias de identificação, tais como a biometria, por exemplo, representando oportunidades comerciais para tais empresas.

Outro ponto que converge entre os agentes relevantes do SBE refere-se à demanda pela facilidade na distribuição e comercialização dos créditos para os cartões usados na bilhetagem. Pelo tamanho da operação de bilhetagem e por sua importância para o transporte público, já que representa o ponto de entrada do usuário no sistema, existe uma convergência de interesses dos agentes para que ela funcione de maneira eficiente. Investimentos são direcionados para tornar possível a virtualização dos procedimentos de compra e recarga, tais como a venda pela internet e o carregamento embarcado.

Além disso, investe-se na ampliação dos pontos de recarga. Essas medidas viabilizam a compra antecipada de créditos e evitam filas, tumultos e deslocamentos desnecessários para os usuários. A rapidez e o conforto na compra e carregamento de créditos, por sua vez, evitam reclamações e 
críticas às instituições, bem como os problemas de imagem do ponto de vista dos usuários. Já para os empregadores, principalmente no caso das grandes empresas, a compra e a inserção de créditos no cartão VEM Trabalhador são operações que podem causar transtornos, gerar necessidades administrativas caso a solução tecnológica empregada não priorize a facilidade na distribuição dos créditos. As empresas de tecnologia interessam-se pela área, uma vez que representa importantes investimentos em tecnologia da informação para que tais facilidades sejam atingidas.

A demanda por produção de informação acerca das operações de transportes também converge interesses entre os agentes do SBE. Do mesmo modo que nos casos anteriores, essa produção de informações assume significados diferentes para os diversos agentes. Enquanto para o Consórcio atualmente o interesse central na produção de informações reside no controle sobre o sistema público de passageiros, para as operadoras, a produção de informações contribui para o controle das rotinas de suas operações de transporte. Os empregadores também se interessam pela produção de informação na medida em que estas facilitam suas rotinas de aquisição e fornecimento do vale transporte e podem ainda representar economia de custos. Já as empresas de tecnologia percebem como uma oportunidade de atualizações tecnológicas e do desenvolvimento de novos produtos e serviços, tais como softwares direcionados para essas finalidades.

A demanda por segurança dentro dos ônibus que circulam pelo sistema, por sua vez, torna-se um importante elemento de convergência, capaz de unir os diferentes agentes em defesa do SBE, pois que se trata de uma das principais demandas de uma sociedade assombrada por episódios de violência nos centros urbanos.

Para que a articulação seja possível, interesses particulares e antagônicos ficaram de fora dessa cadeia de equivalência. Contudo, interferem no equilíbrio da cadeia, podendo levar à sua reconfiguração. E quais foram as demandas desse tipo expressas no corpus de pesquisa?

A demanda particular com mais impacto na configuração do sistema é a disputa pela gestão do $\mathrm{SBE}$, que ocorre entre a Urbana e o Consórcio Grande Recife. A gestão do sistema não significa apenas o controle do Sistema Central de Processamento de Dados e seus servidores, mas representa a posição hegemônica nas definições em relação ao sistema de bilhetagem e suas funcionalidades. Apesar das convergências apresentadas anteriormente, a disputa pela gestão, de certa forma, tem imobilizado o desenvolvimento do SBE da RMR.

A integração temporal pode ser apontada como a outra demanda particular. Foi defendida por setores do Consórcio Grande Recife e sinalizada pelos usuários e seus empregadores, ao criticarem a atual integração fechada pelos problemas a ela associados, e por acreditarem que a integração aberta poderia representar uma redução nas despesas com deslocamento dos usuários do SBE e gastos com infraestrutura. Por outro lado, na medida em que a integração temporal envolve riscos na manutenção da arrecadação das operadoras, tal demanda encontra relutância entre os empresários de transporte, atuais gestores do sistema, assim como do sindicato que os representa.

Outras demandas particulares foram expressas, como se pode observar na Figura 1. São elas: comunicação direta com os sistemas gerenciais, expressa pelos empregadores; e modelo de negócio, novos nichos e atualização tecnológica, expressas pelas empresas de tecnologia. Tais demandas ficaram fora da articulação que deu origem à cadeia de equivalência, uma vez que não foram compartilhadas pelos agentes hegemônicos.

São antagônicas aquelas demandas dos usuários que giram em torno das mudanças na configuração dos cartões, tanto no que se refere às regras de uso, como no que concerne a possibilidades de criação de novos perfis. Outra solicitação na contramão dos interesses hegemônicos do SBE da RMR é a defesa dos usuários de um aumento de sua representação nos conselhos deliberativos, o que implicaria a mudança nas regras de representação desses agentes nos colegiados. São antagônicas, pois sua incorporação requer uma nova articulação, incluindo novas funcionalidades fora daquelas estabilizadas na cadeia de equivalência, promovendo uma reconfiguração no sistema.

Assim, percebe-se que os grupos sociais relevantes do SBE articulam-se em cadeias de equivalência, constituindo discursos que os tornam hegemônicos sobre os demais grupos. Como foi observado, isso ocorre em torno de uma articulação de demandas, com base na qual são estabelecidos significados dominantes ao SBE. Para isso, agentes hegemônicos do sistema dispõem de instrumentos de regulação, do poder financeiro e da fixação dos discursos, já que são as vozes oficiais do Sistema. Diante de um campo permeado por assimetrias de poder, outros agentes não hegemônicos não são ouvidos, tampouco os interesses relativos a suas posições são considerados, quando não se integram às equivalências. 


\section{CONCLUSÃO}

No mundo contemporâneo, as atividades cotidianas encontram-se mediadas por dispositivos tecnológicos, dentre os quais os SBEs, sistemas que se capilarizam com a difusão dos sistemas inteligentes de transporte, apontados como importantes para a solução dos crescentes problemas de mobilidade urbana. Em um levantamento realizado com vários SBEs implantados no Brasil, foi observada a existência de grande variação no que se refere ao formato desses sistemas. Tal fato indica que a configuração dos sistemas de bilhetagem envolve mais do que a dimensão técnica voltada para as funcionalidades, ou ainda aspectos legais e econômicos. Dimensões sociais e políticas contribuem para definir o funcionamento de um SBE.

Nesse sentido, analisou-se o SBE da Região Metropolitana do Recife com o objetivo de ampliar a compreensão dos sistemas de bilhetagem eletrônica, tendo como base as teorias da construção social da tecnologia (BIJKER; HUGHES; PINCH, 1987), e do discurso (LACLAU; MOUFFE, 2001) que possuem conceitos para analisar as dimensões sociais e políticas daqueles sistemas.

Após a análise das demandas, convergências, particularidades e antagonismos encontrados nos discursos sobre o SBE da RMR, pode-se considerar que este é um sistema de informação, tecnológico e discursivo cuja articulação ocorre em torno de demandas relacionadas a funcionalidades operacionais - controle e fiscalização - deixando de fora outras demandas, dentre as quais aquelas que poderiam atender mais diretamente às demandas por mobilidade dos usuários.

Compreende-se, portanto, que, antes de ser um instrumento transparente de gestão, os SBEs são mediações opacas, carregadas de interesses ao redor dos quais seus agentes articulam-se para torná-los possível. Desse modo, sua capacidade para contribuir diretamente com o estabelecimento de políticas tarifárias flexíveis, integração temporal ou novos formatos de cartões, além de outras demandas relacionadas à melhoria da mobilidade depende de simetrias entre os agentes relevantes no campo discursivo, de modo que novas convergências possam ser estabelecidas para disputar a hegemonia.

A ausência das demandas dos usuários na cadeia de equivalência e a falta de representação de grupo nas decisões relacionadas aos sistemas de bilhetagem eletrônica remetem-nos à questão dos limites da atual gestão do processo de configuração do SBE da RMR no que se refere a uma participação plural nas decisões acerca daquele sistema. De modo geral, tais decisões são tomadas pelo Conselho Superior de Transporte Metropolitano (CSTM), formado por representantes do Governo do Estado, Prefeituras de Recife e Olinda, Câmaras Municipais de Recife e Olinda, Companhia de Trânsito e Transporte Urbano (CTTU), Superintendência de Trens Urbanos do Recife (METROREC), Departamento Estadual de Trânsito de Pernambuco DETRAN-PR, Sindicato das Empresas de Ônibus (URBANA), Agência Reguladora de Pernambuco (ARPE) e 4 representantes dos usuários, sendo um deles estudante, um outro usuário com gratuidade e dois usuários comuns, em um total de 19 conselheiros. Aqui, salienta-se a importância para a gestão dos SBEs de uma Governança, conforme Hansen e Sorensen (2005), que permita a participação de todos os seus agentes, possibilitando, assim, que discursos não hegemônicos igualmente sejam ouvidos e considerados na configuração dos sistemas.

Por fim, compreende-se que o discurso dos SBEs é formado por relações de poder, nos quais a política reside não como exceção - ou um desvirtuamento do caminho técnico -, mas como a lógica que torna possível igualmente a cooperação e coexistência de grupos com interesses nem sempre possíveis de conciliar. 
THE ELECTRONIC TICKETING SYSTEMS AND THEIR MULTIPLE DIMENSIONS: A STUDY ABOUT THE SBE OF THE METROPOLITAN AREA OF RECIFE

\begin{abstract}
The implementation of electronic ticketing systems (ETS) involves a number of choices beyond those of a technical nature. To broaden the understanding of these systems, we researched the Metropolitan Eletronic Voucher (MEV) of ETS in the Metropolitan Area of Recife, based on the theory of social construction of technology and discourse theory, which enabled us to understand the social and political dimensions of that system. This on the grounds that such knowledge can serve as the basis for implementing most appropriate practices to manage these systems. To analyze the construction of discourses by relevant groups of the system, we used the following corpus: the websites of ETSs, articles of experts in the area, news from press and personal interviews with agents of the ticketing system. After analyzing the demands, convergences, peculiarities and contradictions found in discourse about the ETS in metropolitan area of Recife, we consider that it is a system whose articulation occurs around demands related to operational functions - control and supervision not taking into account other needs, among which are those that could more directly meet the demands for mobility of users.
\end{abstract}

Keywords: Eletronic ticketing system. Discourse theory. Social construction of technology.

\title{
REFERÊNCIAS
}

ASSOCIAÇÃO NACIONAL DE TRANSPORTES PÚBLICOS (ANTP). Integração nos transportes públicos. Brasília: ANTP, 2007. v. 5. (Série Cadernos Técnicos).

ASSOCIAÇÃO NACIONAL DE TRANSPORTES PÚBLICOS (ANTP). Sistemas Inteligentes de

Transporte. [2012]. Disponível em: <http://issuu.com/efzy/docs/ct_its201208/1?mode=embed\&la yout=http://portal1.antp.net/issuu/whiteMenu/layout.xml>. Acesso em: 5 jun. 2015.

ASQUINI, A.; FONSECA, H. A bilhetagem eletrônica avança. Revista Movimento, São Paulo, n. 4, p. 40-49, dez. 2005.

BENAKOUCHE, T. Interação Social e Técnica: um novo paradigma? Ciência e Trópico, Recife, v. 27, n. 1, p. 7-19, jan./jun. 1999.

BEST, N. L. Cooperação e Multi-level Governance: o caso do Grande Recife Consórcio de Transporte Metropolitano. 2011. 215 f. Dissertação (Mestrado em Administração de empresas) Fundação Getúlio Vargas, São Paulo.

BIJKER, W.E.; HUGHES, T. P.; PINCH, T. J. (Ed.). The Social Construction of Technological Systems: New Directions in the Sociology and History of Technology. Cambridge, MA: The MIT Press, 1987.

BIJKER, W. E.; BAL, R; HENDRIKS, R. Paradox of Scientific Authority: the role of scientific advice in democracies. Cambridge, MA:The MIT Press, 2009.

BURITY, J. A. Desconstrução, hegemonia e democracia: o pós-marxismo de Ernesto Laclau. In: GUEDES, M. A. (Org.). Política e Contemporaneidade no Brasil. Recife: Bagaço, 1997. p. 29-74.

CORRÊA, M. I. S. No Vai e VEM da Mobilidade Urbana: Perspectivas Discursivas dos Sistemas de Bilhetagem Eletrônica. 2013. 217f. Tese (Doutorado em Administração) - Programa de Pósgraduação em Administração da Universidade Federal de Pernambuco, Recife, 2013.

GAMA, l; RECENA, L. G.; ELOY R. X. Evolução na utilização da bilhetagem eletrônica: do "simples" controle da arrecadação para instrumento de pesquisa. In: CONGRESSO BRASILEIRO DE TRÂNSITO, 15., 2005. Anais... Brasília: ANTP, 2005.

GLYNOS, J. The grip of ideology: a Lacanian approach to the theory of ideology. Journal of Political Ideologies, Nottingham, UK, v. 6, n. 2, p. 191-214, 2001.

HANSEN, A.; SORENSEN, E. Polity as Politics: studying the shaping and effects of discursive polities. 
In: HOWARTH, D.; TORFING, J. (Ed.). Discourse theory in european politics: identity, policy and governance. New York: Palgrave Macmillan, 2005. p. 93-116.

HOWARTH, D; STAVRAKAKIS, Y. Discourse theory and political analysis: identities, hegemonies and social change. Manchester: Manchester University, 2000.

HUGHES, T. P. The Evolution of Large Technological Systems. In: BIJKER, W. E.; HUGHES, T. P.; PINCH, T. J. (Ed.). The Social Construction of Technological Systems: New Directions in the Sociology and History of Technology. Cambridge, MA:The MIT Press, 1987. p. 51-82.

LACLAU, E. Inclusão, exclusão e a construção de identidades. In: AMARAL JUNIOR, A.; BURITY, J. A. (Org.). Inclusão Social Identidade e Diferença: Perspectivas pós-estruturalistas de análise social. São Paulo: Annablume, 2006. p. 21-39.

LACLAU, E.; MOUFFE, C. Hegemony and Socialist Strategy: Towards a Radical Democratic Politics. 2. ed. London: Verso, 2001.

LATOUR, B. Science in action: how to follow scientists and engineers through society. Cambridge, MA: Harvard University Press, 1987.

LUBECK, R.; LADEIRA, W.; COSTA, J. Gestão da informação no setor de transporte público: uma análise de conteúdo no caso da bilhetagem eletrônica. In: Seminários em Administração (SEMEAD), 11., 2008. Trabalhos apresentados. São Paulo: FEA/USP, 2008. Disponível em: <http://www.ead. fea.usp.br/semead/11 semead/resultado/trabalhosPDF/696.pdf>. Acesso em: 12 abr. 2012.

MARÇAL, M. C. O discurso do sistema tecnológico Porto Mídia: um estudo no campo da economia criativa e artes digitais. 2014. 194f. Tese (Doutorado em Administração) - Programa de Pós-graduação em Administração da Universidade Federal de Pernambuco, Recife, 2014.

MARTINELLI, J.; AROUCHA, M. Fase atual da bilhetagem eletrônica. Série Cadernos Técnicos, Brasília, v. 8, p. 76-99, maio 2012. Disponível em: <http://issuu.com/efzy/docs/ct_its201208/1?mode =embed\&layout=http://portal1.antp.net/issuu/whiteMenu/layout.xml>. Acesso em: 5 jun. 2015.

NTU - ASSOCIAÇÃO NACIONAL DAS EMPRESAS DE TRANSPORTES URBANOS. Pesquisa bilhetagem eletrônica nos municípios brasileiros com mais de 100 mil habitantes 2010. Brasília: Associação Nacional das Empresas de Transportes Urbanos, 2010.

ORLANDI, E. P. Análise do discurso: princípios e procedimentos. 4. ed. Campinas: Pontes, 2002.

VALE ELETRÔNICO METROPOLITANO (VEM). Sobre o Vem. Disponível em: <http://www. vemgranderecife.com.br/?page_id=2>. Acesso em: 30 maio 2014.

WINNER, L. Do artifacts have politics? In: MACKENZIE, D.; WAJCMAN, J. (Ed.). The Social Shaping of Technology. Philadelphia: Open University Press, 1985. p. 26-38. 